\title{
Erratum
}

\section{Note on effects of joint replenishment and channel coordination for managing multiple deteriorating products in a supply chain}

\author{
BC Giri and T Maiti \\ Journal of the Operational Research Society (2012) 63, 1177. doi:10.1057/jors.2012.78
}

Correction to: Journal of the Operational Research Society (2012) 63, 861-863. doi:10.1057/jors.2011.87

In the print version of the above viewpoint article, Table 1 was missing. Please find the Table below:

Table 1 Optimal results for low and high levels of deterioration rate and unit cost of the retailer

\begin{tabular}{|c|c|c|c|c|c|}
\hline Policy & Optimal decisions & Low deterioration rate & High deterioration rate & Low unit cost & High unit cost \\
\hline \multirow[t]{7}{*}{$I$} & $T_{1}^{*}$ & 1.4434 & 0.9252 & 1.2844 & 1.0172 \\
\hline & $T_{2}^{*}$ & 2.9326 & 1.9659 & 2.6837 & 2.1182 \\
\hline & $T_{3}^{*}$ & 2.1826 & 1.4191 & 1.9606 & 1.5500 \\
\hline & $T_{4}^{*}$ & 1.6415 & 1.0615 & 1.4698 & 1.1620 \\
\hline & $T C_{r}$ & 8307 & 11841 & 7779 & 12343 \\
\hline & $T C_{m}$ & 2254 & 4160 & 2754 & 3482 \\
\hline & $T C$ & 10561 & 16001 & 10533 & 15825 \\
\hline \multirow[t]{4}{*}{$I I$} & $T^{*}$ & 1.0979 & 0.7095 & 0.9803 & 0.7782 \\
\hline & $T C_{r}$ & $7757(-6.62 \%)$ & $11000(-7.10 \%)$ & $7172(-7.80 \%)$ & $11569(-6.27 \%)$ \\
\hline & $T C_{m}$ & $2182(-3.19 \%)$ & $4473(+7.52 \%)$ & $2830(+2.76 \%)$ & $3565(+2.38 \%)$ \\
\hline & $T C$ & $9939(-5.89 \%)$ & $15473(-3.30 \%)$ & $10002(-5.04 \%)$ & $15134(-4.37 \%)$ \\
\hline \multirow[t]{7}{*}{$I I I$} & $T_{1}^{* *}$ & 2.6715 & 1.8174 & 2.4255 & 1.9530 \\
\hline & $T_{2}^{* *}$ & 5.2736 & 3.6344 & 4.8542 & 3.8825 \\
\hline & $T_{3}^{* *}$ & 3.9791 & 2.7052 & 3.6230 & 2.9072 \\
\hline & $T_{4}^{* *}$ & 3.1562 & 2.1773 & 2.8909 & 2.3242 \\
\hline & $T C_{r}$ & $8637(+3.97 \%)$ & $12454(+5.18 \%)$ & $8175(+5.09 \%)$ & $12864(+4.22 \%)$ \\
\hline & $T C_{m}$ & $1212(-46.23 \%)$ & $2117(-49.11 \%)$ & $1454(-47.02 \%)$ & $1810(-48.02 \%)$ \\
\hline & $T C$ & $9849(-6.74 \%)$ & $14571(-8.94 \%)$ & $9629(-8.58 \%)$ & $14674(-7.27 \%)$ \\
\hline \multirow[t]{4}{*}{$I V$} & $T^{* *}$ & 2.3108 & 1.6325 & 2.1316 & 1.7317 \\
\hline & $T C_{r}$ & $8015(-3.52 \%)$ & $11516(-2.74 \%)$ & $7485(-3.78 \%)$ & $12001(-2.77 \%)$ \\
\hline & $T C_{m}$ & $818(-63.71 \%)$ & $1487(-64.25 \%)$ & $1010(-63.32 \%)$ & $1243(-64.30 \%)$ \\
\hline & $T C$ & $8833(-16.36 \%)$ & $13003(-18.74 \%)$ & $8495(-19.35 \%)$ & $13244(-16.31 \%)$ \\
\hline
\end{tabular}

Figure in '()' indicates \% change with respect to the corresponding result under Policy $I$. 